\title{
Small Acts of Entrepreneurship Transcend the Business Realm
}

\author{
Donna De Carolis (Drexel University)
}

KEYWORDS: Entrepreneurship, Innovation, Management, Women, student entrepreneurs, Student innovators.

The surge of enthusiasm for entrepreneurship bellows from the halls of government, the offices of corporations, the hashtags of social media, and the classrooms of academia. As a society, here in the United States and globally, we are enthralled with the potential that entrepreneurship promises for us in terms of economic and societal welfare -- and rightly so. New job creation is mostly a function of new business ventures. Innovative ideas, while not confined to start-ups, spring from them in leaps and bounds and grow in unpredictable ways. Through entrepreneurship, problems are identified, solutions created, existing paradigms are challenged, markets and industries are disrupted and, in the aggregate, society advances.

In the minds of the general public, the phenomena of entrepreneurship is synonymous with the celebrity of the entrepreneur. Both the act of entrepreneurship and the person who is the entrepreneur remain indistinct from each other. When we imagine a start-up, we conjure images of the passionate entrepreneur, the person who takes the risk, defiantly marches ahead in building a company, and ultimately prospers from their success. The entrepreneur becomes larger than life; a different type of person; unlike the rest of us. We look at the highly visible entrepreneur and rarely appreciate the extent of their challenges and experiences.

\section{To 'swim out and grasp'}

This is unfortunate because it suppresses the reality that all of us possess the capacity to be entrepreneurial. The word "entrepreneur" originally comes from the combination of two Latin words "entre", to swim out, and "prendes", to grasp, or capture. The French evolution of the word translates to one who undertakes. If we embrace these original meanings of the word "entrepreneur" - an act of reaching out and capturing, and undertaking -- then we open up an interpretation of those moments in our lives when we think and behave

as an entrepreneur. I call these actions "small acts of entrepreneurship."

Small acts of entrepreneurship extend beyond the realm of business or profession - they occur throughout our lives - although we don't label them as such. When we "swim out" from what we normally do and grasp or undertake a new opportunity, we are engaging in small acts of entrepreneurship. It could be moving to a different location, changing careers, evolving through a personal challenge or crisis. We are born "entrepreneurs" and we don't realize the extent to which we manifest that character. For many of us, the norms of society, culture, education, family and more tame or limit our entrepreneurial traits in all aspects of our lives. We learn the comfort and safety of doing more of the same; we begin to fear as opposed to consider new opportunities.

So the term entrepreneur has been projected to the larger-than-life "character" in a business context dismissing and dispelling the view that there is an entrepreneur in all of us. Yet we all have the capacity to think and act innovatively, to embrace change, to overcome challenges, to look for options, to be resilient.

\section{A new role for higher education}

This established paradigm of the "entrepreneur" has spilled over into how higher education teaches entrepreneurship. In higher education we have, knowingly or not, adopted the general consensus that we can't teach the person to be the entrepreneur; so we have resorted to teaching the process and labeling it entrepreneurship education.

The consequences of this merger of concepts is manifested in the underlying assumptions embedded in the design of most entrepreneurship curricula in higher education, which focus on the process of 
entrepreneurship. Hence we witness courses such as Entrepreneurial Marketing, Entrepreneurial Law, Entrepreneurial Finance \& Accounting and the everpopular Business Planning classes. Included in required coursework for entrepreneurship majors are also standard courses in mergers and acquisitions, sales, operations, etc. Certainly, such degree programs provide a strong knowledge base in the process of starting and running a company.

Yet, constraining the meaning of the word "entrepreneur" to equate with someone who starts a new venture, narrows how we develop our programs. It puts us into the building block of "siloed' courses to create new ventures devoid of creating the entrepreneur.

As an academy, we have leapt to two conclusions: that being an entrepreneur is about starting a new venture and that by teaching the process, we will produce entrepreneurs, largely ignoring the coaching and experience requisite to producing an entrepreneurial mindset. Any curricula that purports to teach about entrepreneurship is obliged to include the development of an entrepreneurial attitude. This involves more than simply telling students that they will fail; it means having them experience failure and finding a way back...in other words, small acts of entrepreneurship.

This translates into planning a suite of entrepreneurship courses that includes multiple opportunities for starting, failing and pivoting. It involves an apprenticeship approach and committed instructors and mentors and peers who intertwine the classroom concepts simultaneously with the experience. While planning and implementing such a curriculum is a rigorous task, it is the most effective way of delivering an entrepreneurship curriculum that actually produces entrepreneurs - those with an entrepreneurial mindset.

\section{Beyond business}

As educators, we can reinforce the idea that beyond the business context, all of us engage in small acts of entrepreneurship in our personal lives. Including courses, topics and content in entrepreneurship curriculum that underscore the true meaning of the term "entrepreneur" enhances the teaching of the process of entrepreneurship. This gives students an entrepreneurial tool kit that will be relevant in all aspects of their lives.
We know that we are graduating students into a labor market that values innovative thinkers; that increasingly relies on contract or contingent labor; and that is adopting artificial intelligence and automation at a quick pace. This is an economy in which coming generations of graduates will have multiple jobs in their careers that most likely will include self-employment and/or running a company (or two) while being fully employed.

Our small acts of entrepreneurship enhance resilience, self-esteem and innovative thinking. Imagine how higher education could contribute to eliciting the inner entrepreneur in all of us through embracing the broader and more accurate conceptualization of "the entrepreneur" and infusing the experience throughout our programming. 